\title{
Chomsky's I-languages: Rethinking catastrophic changes
}

\author{
David W. Lightfoot \\ Georgetown University \\ lightd@georgetown.edu
}

\begin{abstract}
Languages sometimes undergo major shifts, when multiple phenomena change together, often called catastrophes, phase transitions, or saltations. Recently Emonds and Faarlund (2014) argued for a major shift when the syntax of Middle English was largely replaced by Scandinavian syntax. Their proposal was met with hostility by historians of English, committed to the gradualness of change. However, if one thinks in terms of internal languages holding of individuals ('I-languages' in Chomsky 1986) and not of languages as wholes or Chomsky's 'E-language', we can follow the methods of population biology and understand better the mechanisms of such major shifts.
\end{abstract}

Keywords: internal languages; population biology; Scandinavian influence on Middle English; phase transitions; language replacement

\section{Discontinuities and abstractions}

Nineteenth-century neogrammarians developed a theory of sound change but nothing parallel for syntax, morphology or other aspects of language. This was their legacy for American structuralists, who also limited their theoretical work largely to what we now call phonology, alongside more narrowly descriptive work in syntax and morphology. A typical textbook treatment of the field from the 1950s depicts language change as change in sounds, and, crucially for our discussion here, as necessarily gradual: 'we described sound change as a gradual change in habits of articulation and hearing, taking place constantly, but so slowly that no single individual would ever be aware that he might be passing on a manner of pronunciation different from that which he acquired as a child. This gradualness is extremely important' (Hockett 1958, 439). Hockett goes on, 'When a person speaks, he aims his articulatory motions more or less accurately at one after another of a set of bull's-eyes, the allophones of the language' (ibid., 440). Speakers are 'quite sloppy in [their] aims most of the time' and over time may hit different targets, hence language change. So for many in the 1950s, language change was gradual change in sound production. 
Paul Kiparsky $(1968,175)$ took this view to be tantamount to seeing a language as a 'gradual and imperceptibly changing object which smoothly floats through time and space', changing, for example, from Old, to Middle, to Early Modern, and then to Present-Day English, with various gradations in between but no major disruptions. That view is still often expressed, as we shall see, but it underestimates the scale of possible changes.

Early generativists dealing with change, on the other hand, Kiparsky and his colleagues, worked with abstract grammars encompassing syntax and morphology alongside sounds and saw them changing as children encountered new ambient language. An abstract grammar was a system with its own structures and computational operations, a biological object acquired by children and represented in people's brains. Kiparsky went on, 'the transmission of language is discontinuous, and a language is recreated by each child on the basis of the speech data it hears'. If one abstract structure in a generative system changes, that typically has multiple consequences for the structures and expressions generated by the system, hence discontinuities and possibilities for large-scale changes.

More recently, Lightfoot (2017b) notes that change is often gradual to the point of being imperceptible but that, when we use a telescopic lens, we see major discontinuities that arise from the abstractness of the structures, as we shall see below. I imagined a syntactician walking the 400 miles from Berlin to Amsterdam, covering 10 miles a day and hearing no significant differences in the speech of people she meets at breakfast and at dinner, not even on the day that she crosses the border from Germany into the Netherlands. How then to account for the paradox that the German of Berlin is quite different from the Dutch of Amsterdam?

Lightfoot reiterated Kiparsky's view that grammars are invented by children, not transmitted wholesale to the next generation, and he summarized arguments for some major and now well-understood discontinuities. He showed how the paradox might be explained under a non-standard approach to language acquisition that employs a clear distinction between sociologically defined external language and the internal languages of mind/brains (see below); crucially, children discover or invent the abstract structures of their internal languages.

Given the role of abstract structures, there may be new phenomena in the input that trigger a single change at the abstract level, yielding a new structure that serves to generate many new phenomena that enter the language at the same time. This approach to language change (Lightfoot 1979) anticipated neo-Darwinian biologists' appeal to punctuated equilibrium, in turn based on Ernst Mayr's model of geographic speciation (Eldridge \& 
Gould 1972), and their rejection of Darwin's gradualism. There followed a focus on structural shifts across many historical disciplines, some known as 'catastrophes' (Thom 1972) ${ }^{1}$ or 'phase transitions' at different stages of investigation within the successive frameworks of catastrophe theory in the 1950s and 60s, chaos theory (Gleick 1987), and synergetics (Haken 1984) in the 1970s and 80s, and complexity science more recently (Casti 1994; Kauffman 1995).

Linguists have identified such saltations and understood them in terms of children acquiring new systems when exposed to new ambient language. Sometimes several phenomena change simultaneously and one can explain the simultaneity by arguing that there is a single change at the abstract level of the internal system from which the new phenomena follow. The task then is to show how the new system might have been acquired by children: how new ambient language (i.e., new external language) triggers new internal systems. Rich and deep explanations have been developed for some syntactic changes and explanations have been deepened by a conceptual shift in the 1980s, which has not received the attention it deserves and might be characterized as the great individualization. Chomsky (1986) elaborated his famous 1965 idealization of an ideal speaker-hearer in a completely homogeneous speech community. He distinguished external language and internal, individual languages (below), changing his mind on the fundamental nature of grammars and this had profound consequences for the way in which we can think about catastrophic changes.

\section{Individualism}

As we celebrate Noam Chomsky's 90th birthday, I was asked to write about the effects of his ideas for work on language change. Of course, Chomsky has done so much fundamental work on language that his ideas have had pervasive consequences for many fields. His analytical work has had consequences for the detailed syntactic structures postulated for all languages that diachronic syntacticians have worked on. Cataloguing that work would be a huge task and here I will focus on one fundamental idea about what we work on, where Chomsky has taken somewhat different

${ }^{1}$ The French see catastrophes frequently, as noted by others; three-syllable French catastrophes /katastrof/, with stress on the final syllable, seem less catastrophic than four-syllable English /katastrofiz/ with antepenult syllable stressed. So French and English 'catastrophes' have somewhat different meanings as well as different pronunciations. 
stances in his early and later work: the nature of grammars. Chomsky made a shift in 1986, which has not been fully understood and certainly not properly implemented in analyses, leading to many misunderstandings.

Chomsky $(1965,3)$ famously defined the field as 'concerned primarily with an ideal speaker-listener, in a completely homogeneous speechcommunity, who knows its language perfectly and is unaffected by such grammatically irrelevant conditions as memory limitations, distractions, shifts of attention and interest, and errors (random or characteristic) in applying his knowledge of the language in actual performance'. Under this idealization, linguists wrote grammars for complete languages like Finnish, English, Japanese, and so on, capturing the competence of idealized speaker-listeners.

However, Chomsky (1986) complemented this idealization with a distinction between external E-language and internal I-languages, very different kinds of things. E-language is a mass sociological concept, a group phenomenon, external language out there, the kind of unanalyzed thing that anybody might hear and it includes the Primary Linguistic Data (PLD), also unanalyzed, that trigger the new system. I-languages, on the other hand, are internal, individual systems that emerge in children according to the dictates of the inherent language capacity and to the demands of the ambient external language to which they are exposed and which they seek to understand and analyze, i.e., to parse.

To parse is to assign detailed linguistic structure to E-language expressions, identifying the categories to which words belong, their indexical relations, their cases, how heads project to phrasal categories, etc. And parsing is key to language acquisition by children. One way of thinking about this is to view structural relations as assigned by a person's I-language, not by a distinct parser. Lightfoot (2020) argues that there is no distinct parser, a separate cognitive faculty; rather, a person assigns structural properties through their private I-language, which is gradually enriched as children grow their I-languages from the very rudimentary structures of a two-year old to the richer analyses of a three-year old. Under this view, historical change consists of new parses for similar strings of words.

I-languages are properties of individual mind/brains, consisting of abstract structures. Individuals acquire an individual, private I-language, characterizing their particular form of English and not the external language of English as a whole or even the English of a person's speech community.

Chomsky now echoed Wilhelm von Humboldt (1836), who distinguished the language of individual citizens from the language of a nation, 
and Hermann Paul, who asserted that 'die reelle Sprache nur im Individuum existiert' ('real language exists only in individuals', Paul 1877, 325, ) and later that 'Wir müssen eigentlich so viele Sprachen unterscheiden als es Individuen gibt', ('we must in fact distinguish as many languages as there are individuals', Paul 1880, 31). Chomsky (1986, 32) also cites Jespersen as another 'internalist' precursor of some of his views.

Put differently, 'English' is not recursively enumerable; there is no system that will generate the sentences of English, partly because of internal contradictions: an expression like Kim might could read this is an expression of English in Arkansas but not in New York or Cornwall. Gwain ee $t^{\prime}$ Exeter 'is he going to Exeter?' is said in Cornwall, but not in New York or Arkansas. Under this view, the English language has no more reality than the French liver, English irony, or the Scottish love of whisky; such things do not exist except as abstract idealizations.

Similarly, and relevantly for the catastrophe to be discussed here, there is no recursive device that generates the set of expressions in surviving English texts from the 13th and 14th centuries. Rather there is a set of I-languages that generates what we see in the texts and we study language change in part as the spread of new I-languages, using the methods of population biology. There is no biologically coherent notion of English, certainly not an object being transmitted steadily from one generation of language users to another. If languages are not transmitted, there are many damaging consequences for traditional ways of thinking about language change, but that is a topic for other days.

Chomsky made his move toward I-languages at about the same time as Tony Kroch introduced his idea of competing, co-existing grammars (Kroch 1989): individuals often have more than one internal system and may use different systems at different times in a kind of internal multiglossia (see also Yang \& Roeper 2011). In this thinking, we may go beyond Paul and argue that there are many more I-languages than there are individuals, if individuals may use more than one I-language.

These ideas have had profound consequences for syntactic analyses and, in particular, for thinking about syntactic change, consequences that have still not been fully thought through. They enable us to gain new understanding of catastrophes or phase transitions, when many phenomena change at the same time, or domino effects when changes occur in rapid sequence. The ideas of E-language and I-languages suffice to account for language acquisition and we do not need the conventional, sociologically defined notion of English or Estonian. With these notions, linguists do not write grammars for whole languages (which are demonstrably not recur- 
sively enumerable) but for I-languages that capture an individual's linguistic capacity. One views children as inventing their individual, private I-language on exposure to external E-language. Children are born to parse and parsing is key for language acquisition. Children parse the E-language they hear and acquire the categories and structures needed to understand what they hear, and thus they discover and invent the elements of their I-language (Lightfoot 2017a); a person's I-language is the aggregation of the structures permitted by UG and required to understand what she hears. Here I explore these ideas in the context of a recent powerful challenge to the traditional commitment to gradual and imperceptible change.

\section{Anglicized Norse, a catastrophic change, a phase transition}

Emonds and Faarlund (2014), henceforth E\&F, offer a radical challenge to the philologists' conception of English progressing gradually and imperceptibly from one stage to another. E\&F postulate that so-called early Middle English spoken and, crucially for historical linguists, written in the East Midlands in the 12th and 13th centuries and reflecting the results of intensive and extensive contact, represents a new language, which they call Anglicized Norse, having many features of Scandinavian syntax alongside West Germanic words and phonological structures corresponding to Old English antecedents (Trudgill 2016 suggests the alternative 'Norsified English', with a slightly different emphasis). They argued that Anglicized Norse syntax essentially replaced the syntax of Old English. They built on work by philologists and syntacticians who argued for analyses that $\mathrm{E} \& \mathrm{~F}$ construe now as aspects of a more comprehensive phase transition and they muster considerable evidence for their analysis. However, their work has had, it is fair to say, a hostile response from many historical linguists, notably in an issue of Language Dynamics and Change devoted to discussion of their book by several authors and in a review article by Bech and Walkden (2016). The analysis is being rejected and discarded prematurely, I claim; for a more sympathetic view, see Lightfoot (2016). ${ }^{2}$

New I-languages emerge when the ambient external language, experienced by children, changes and E\&F offer an intriguing socio-political history of language used in medieval England. They address several matters that have been raised by historians of English, discussing how England was

${ }^{2}$ Much of the commentary concerns the genealogy of Middle and Modern English but if languages are not transmitted in the way presupposed by the cladograms of people defining language 'families', more radical re-thinking is needed. 
subjugated by Scandinavians for 200 years and then mercilessly by the Normans. In the post-Conquest years, the English and the Scandinavians had a common oppressor. By 1100 all property of any note was in the hands of the Normans; under the Normans 'two previously separate peoples became united in servitude' (E\&F, 41). 'The miserable circumstances gave rise to a complete fusion of two previously separate populations, speakers of Old English and speakers of Scandinavian' (ibid., 43). They intermarried and there was much bilingualism, as often noted (O'Neil 1978). This is when we begin to observe significant Scandinavian influence on the native written language, not when the Scandinavians first arrived and constituted the ruling class. When the two dispossessed Germanic populations had a common enemy, the Scandinavians predominated in trade, agriculture, and in leading the opposition to the French. The Scandinavians settled permanently in the East Midlands and North and seem to have enjoyed notably higher economic status than the native English. A plausible socio-political history of language in England enables us to understand better how eventually the dominant features of external language, both spoken and written, came to be Norse for many people, explaining why children came to acquire Norse syntax, given that their ambient E-language had changed and now incorporated many aspects of Norse syntax. And if they acquired elements of Norse syntax, we understand why there was a wholesale introduction of new constructions in the written language, as Old English became more and more restricted to impoverished and illiterate peasants and eventually died out.

The external history that $\mathrm{E} \& \mathrm{~F}$ provide enables us to understand how the new I-languages that they postulate might have been acquired by children but the substance of their case lies in the linguistic analyses they outline. They tease apart syntactic characteristics of West Germanic (Dutch, Frisian, High and Low German, and their later offshoots Yiddish and Afrikaans) and North Germanic (Mainland Scandinavian: Norse, Norwegian, Danish, Swedish), all well analyzed languages, and argue that Old English, to a large extent, has the characteristics of the former and Middle English the latter. For example, North Germanic has underlying headinitial VPs, West Germanic 'at least partly' head-final; North Germanic has infinitives with a to free morpheme while West Germanic uses inflection; North Germanic has subject raising but West Germanic does not; restrictive relatives are introduced by invariant morphemes in North Germanic but by pronouns marked for case in West Germanic. E\&F examine twenty such structures, which they call 'parameters', and argue that early Middle English speakers began to set them in the North Germanic fashion. 
For all twenty parameters, they offer a plausible demonstration that Old English speakers set them in the West Germanic fashion and early Middle English speakers in the North Germanic fashion. Furthermore, Holmberg (2016) noted strikingly that 'as for syntactic features that Middle English shares with Old English that are not shared with Norse, they don't find any!'. Holmberg also notes that there seem to be other ways in which Middle English adopted Scandinavian characteristics, beyond what E\&F considered, for example the deletion of complementizers and the avoidance of 'that-trace' violations. Whatever the details of each of the twenty structures, there was clearly a major discontinuity between Old and Middle English, as noted by many philologists over a long period, and something requiring explanation.

There is much to be said about all twenty features but it is noteworthy how little is said about them in the commentaries offered so far and how things that are said often turn out to be misconceived - see below. Trudgill (2016) is persuaded that 'Emonds and Faarlund have brilliantly demonstrated that the syntax of my native language owes a great deal to the syntax of [Old Norse] - and very much more than has generally been thought'. Noting E\&F's 'deeply impressive achievement', he laments 'the generativist mindset' of the authors but aspects of the generativist mindset not called on by $\mathrm{E} \& \mathrm{~F}$ in fact strengthen their case, namely the E-/I-language distinction and matters of language acquisition.

E\&F (84-93) offer excellent discussion of the very unusual property of preposition stranding, absent in most Indo-European languages including Old English and West Germanic (except Frisian and Dutch under very special circumstances) but found in the early and modern mainland Scandinavian languages. They also offer good nuanced discussion of the change from head-final VPs to head-initial, recognizing work (e.g., Pintzuk 2002) showing the new V-DP order occurring sometimes in Old English texts.

It is important to note that, whatever the descriptive success with the twenty properties discussed, E\&F attain a remarkable level of explanatory adequacy by postulating that the language of Norse speakers played a major role in triggering the syntactic structures of the English speech community during the early Middle English period (12th and 13th centuries). For example, E\&F discuss the verb-second properties of Old English, which show the complicating property of verb-third when the subject is pronominal and to the left of the finite verb (van Kemenade 1987): welc yfel he mæg don, 'each evil he can do'. Whatever this special property of Old English is, it is absent from Norse and therefore, given their central hypothesis, it is predictably absent from Anglicized Norse and early Middle 
English. By claiming that it was Norse syntactic systems that emerged, E\&F predict that all the twenty relevant properties should have emerged in the first Middle English texts and that they should not have emerged in piecemeal fashion: all the new phenomena involve 'changes' in the direction of North Germanic parameter settings. On another hand, for Bech \& Walkden (2016), for example, this consistency is either accidental or not real.

E\&F write 'The Old/Middle English break very much concerns the structure of the language itself; it is very little connected with how English was used or how it was perceived' (ibid., 28). 'When English began to be written after the [Norman] Conquest, the new characteristics were clearly in the ascendant, most strongly in the former Danelaw [...], while many aspects of Old English (as well as most of its vocabulary) had disappeared or been reduced to remnant percentages, especially in the South and Southwest' (ibid., 29).

\section{Individual languages vs. big data}

E\&F achieve considerable descriptive and explanatory success. However, their account is troublesome for people who believe that language changes only gradually and imperceptibly. In contrast, we can understand why and how the changes E\&F describe should have happened if we think in terms of I-languages being acquired by individuals. We have emphasized that I-languages exist for people and not for languages; there is no grammar of English in any biological sense. Therefore, rather than thinking of 'language change', we need to think less grossly, in terms of the spread of new I-languages. We noted antecedents for this view in the writings of von Humboldt and Paul in the nineteenth century. Von Humboldt, Paul, and modern work take a biological view of languages, as opposed to a social view. At a minimum, different questions arise under each view and the same questions take on quite different complexions; this is worth some reflection.

The overwhelmingly most common view among historians is that language change is gradual and that view seems to drive E\&F's antagonists in Language Dynamics and Change. However, things depend on the units of analysis, the kind of lens used: languages, seen as social entities, change gradually, but I-languages change abruptly.

For example, Fries (1940) looked through a wide-angle lens and found that Old English showed object-verb order $53 \%$ of the time around the year 1000 and that it was gradually replaced by verb-object order, reducing to 
$2 \%$ by the year 1500 . He provided one set of statistics for each century but offered no analysis. Fries' counts ignored the distinction between matrix and embedded clauses, where word orders were different, and he had no analysis of the fact that the finite verb often appeared in second position in simple clauses. If one makes such distinctions, one can count more productively and see that Old English I-languages had object-verb order underlyingly, a system yielding subjects in first and third position, and objects 'extraposed' to the right. Consequently, we find object-verb order uniformly in embedded clauses, but only variably in matrix clauses. In fact, at least two distinct changes took place in I-languages, and took place at different times: object-verb order was replaced by verb-object and the operation moving objects to the right of the verb was lost (Haeberli 2002a;b).

If units of analysis are as gross as Fries', change will look gradual. But one must be wary of 'big data', often gathered these days through digitized corpora that do not make the E-/I-language distinction that is essential to our view. In gathering data from a certain period, say 15th century England, even partially parsed expressions, one must resist the temptation to assume that there must be a device that will generate that collection of data and one must be ready to distinguish data and abstract structures generated by new I-languages and the raw data of E-language that might trigger those new I-languages.

At the other end of the scale, if we use a telescopic lens, the speech of no two people is identical and change is everywhere; all is in flux and languages are constantly changing in piecemeal, gradual, and minor fashion; again we see constant, gradual change. Initial experiences are never entirely the same for two speakers and they may differ in minor and insignificant ways. Some construction type might become more frequent, perhaps as a result of taking on some expressive function. This does not reflect the properties of an I-language itself but the way in which I-languages are used. Such changes in frequency do not reflect a change in I-languages but they do entail a change in the external language for the next generation of speakers, therefore for the PLD triggering the next I-languages. ${ }^{3}$

Not only may external language change gradually, but the very nature of language acquisition ensures a kind of gradualness under circumstances where children experience the speech of their parents and older siblings.

${ }^{3}$ The Primary Linguistic Data are the robust, easily accessible, and structurally simple data that trigger the development of I-languages, a subset of the E-language to which a child is exposed; see Lightfoot $(1989 ; 2012)$ for arguments that they are structurally simple, Degree-0 complex, and drawn from unembedded Binding Domains. 
This works against major discontinuities in the class of expressions and their associated meanings. For example, one generally does not find an I-language yielding more or less uniform object-verb order being replaced abruptly by one yielding uniform verb-object order. Even so, one does find significant discontinuities, as E\&F have shown dramatically, especially in contexts where the output of a parent's native I-language does not contribute as significantly to a child's experience as the I-languages of children who have already acquired elements of Norse syntax. To be sure, there is no reason to believe that there is any formal relationship between the I-languages of parents and children. I-languages are created afresh by every individual and may differ in form from those of the parents, perhaps radically, within the limits of UG. For discussion, see Lightfoot (1999, chapter 4), where I-language changes are viewed as Thom-style catastrophes; there may be gradual change in the temperature of water until there are structural changes at $0^{\circ}$ and $100^{\circ}$ Celsius (Thom 1972; Casti 1994; now see Haeberli \& Ihsane (to appear) for interesting new evidence corroborating one of the best known cases of re-analysis in the history of English). Similarly, E-language may change gradually and trigger a new I-language at a certain point (see Westergaard 2017 for discussion of the gradualness of change from a range of theoretical perspectives).

Whether differences between I-languages are small-scale or large-scale, they do not have temporal properties and changes in I-languages cannot be 'gradual'. Apparent gradualness does not reflect an I-language property, but a mirage, conjured by a failure to distinguish independent change events. E-language may differ in ways that do not trigger a new I-language. However, a natural way for linguists to think of catastrophic changes is to envisage E-language sometimes crossing thresholds, which entail that a different I-language system is triggered. So the inventory of variable properties given by UG (the abstract structures) constitutes the set of fixedpoint attractors, defining the nature of possible changes; an I-language either has some property or not.

\section{Co-existing I-languages}

The ideas of Tony Kroch and his associates on competing grammars and a kind of internalized multiglossia must factor into any thinking about apparent gradualness of change and the spread of new I-languages (for related ideas, see Roeper 1999). Their work enriches grammatical analyses by seeking to describe the variability of individual texts and the spread of a grammatical change through a population. In postulating two (or more) 
co-existing I-languages in an individual, a researcher needs to show not only that the two I-languages together account for a range of expressions used, but also that the two I-languages are learnable under plausible assumptions about children's PLD. Co-existing grammars are subject to exactly the same learnability demands as any other biological grammar.

In fact, this kind of internal diglossia represents an interesting approach to solving significant learnability problems. For example, it offers a way of eliminating an unlearnable distinction between optional and obligatory operations (Lightfoot 1999, 92ff). If grammars do not permit optional operations, as often argued, apparent optionality would be a function of co-existing I-languages. Rather than allowing one I-language to generate forms $a$ and $b$ optionally, one would argue that a person has access to two I-languages, one of which generates form $a$, the other form $b$; the speaker has the option at any given time of using one or other of the I-languages. This move reduces the class of available grammars, eliminating those with optional operations. ${ }^{4}$

This, in turn, entails that, when Old English texts show verb-second phenomena sometimes, that cannot entail that Old English I-languages had a device generating verb-second order optionally. Rather, there must have been competing I-languages, one generating verb-second order and the other not. Certain speakers have access to just one I-language; other speakers have access to the other I-language; and others have access to both systems in an internalized multiglossia.

On the view developed by Kroch, 'change proceeds via competition between grammatically incompatible options which substitute for one another in usage' (Kroch 1994, 180). One reason for believing that this view of change through competing systems is along the right lines is that alternating forms cluster in their distribution, and the clustering follows from how sets of I-languages unify the forms. We do not find free variation, but oscillation between two (or more) fixed points. This is reflected in the Constant Rate Effect of Kroch (1989) and in the fact that writers may alternate between the old and new systems, using both I-languages sometimes within the same sentence (for example, Shakespeare alternates between an old I-language with ${ }_{\mathrm{I}} \mathrm{V}$ structures and a newer I-language without such structures, resulting from verb movement, as discussed in Lightfoot 2006, 98).

${ }^{4}$ Wallenberg (2016) gives a fascinating analysis in these terms of the very slow disappearance of extraposed relative clauses in four European languages. For alternative approaches to apparent optionality, see Adger (2006) and Biberauer \& Richards (2006). 
Because structures are abstract, changing one structure or one categorization may entail a range of new surface phenomena. The Constant Rate Effect entails that all surface phenomena reflecting the new I-language property show usage frequencies changing at the same rate, but not necessarily at the same time. This is easy to understand if one I-language is replaced over time by another, and if that change takes place in a winner-take-all competition between the two systems. We do not find complex arrays of linguistic data changing randomly. Instead, they tend to converge toward a relatively small number of patterns or attractors, in a kind of 'anti-chaos' in the sense of Kauffman (1995). The points of variation defined by the theory of grammar constitute the attractors and the co-existing I-languages define the points of oscillation.

When we view an individual's language capacity as characterized by a private, personal I-language, then the spread of a new I-language across a speech community will be approached through the methods of population biology. An individual may be exposed to PLD that differ from what anybody else has been exposed to. This could happen because of population movements, new patterns of bilingualism, adult innovations, or perhaps because the PLD are truncated in some way, not including earlier expressions or not including them with the same frequency as a generation earlier. Or the kind of massive demographic change described by E\&F.

One individual might select a structure differently from others in her community and, in that event, will produce different utterances. These new expressions, in turn, affect the linguistic environment, and she will now be an agent of further change, reinforcing the PLD that might trigger another instance of her new I-language in a younger sibling. As younger siblings pick the same structures as their older sister, so other people's PLD will differ and a chain reaction is created. In this way a new I-language may spread analogously to what has been observed in population genetics, replicating aspects of evolutionary change.

\section{Population dynamics and a computer simulation}

Partha Niyogi and Bob Berwick $(1995 ; 1997)$ produced a computer model that analyzed change in this way and derived trajectories of changes; the model was enriched by Niyogi (2006). They postulate a learning theory with three sub-components: a theory of grammar, a learning algorithm by which a child generates grammars on exposure to data, and PLD. They imagine a population of child learners, a small number of whom fail to converge on pre-existing grammars. After exposure to a finite amount of data, 
some children converge on the pre-existing grammar, but others attain a different I-language.

\footnotetext{
'The next generation will therefore no longer be linguistically homogeneous. The third generation of children will hear sentences produced by the second - a different distribution - and they, in turn, will attain a different set of grammars. Over successive generations, the linguistic composition evolves as a dynamical system.'

(Niyogi \& Berwick 1997, 2)
}

Emergence of a new I-language, in this simulation, is a logical consequence of specific assumptions about the theory of grammar, the learning algorithm, and the PLD. Interestingly, their model yields different trajectories for different changes. A common trajectory is the familiar S-curve (Weinreich et al. 1968; Kroch 1989): a change may begin gradually, pick up momentum, and proceed more rapidly, tailing off slowly before reaching completion. The success of Niyogi and Berwick is to build a dynamical system from a parameterized system and a memory-less learning algorithm. As a result, they derive the S-curve rather than build it into their model as a specific assumption. Further, the model entails that changing elements of the theory of grammar or of the learning algorithm may yield different trajectories, including trajectories other than the S-curve. That means that their model may, in principle, be amended in light of the way that it matches the actual trajectory for specific changes in specific languages. This offers a new empirical demand for theories to meet, in addition to demands of learnability, coverage of data, etc.: theories can be expected to provide the most accurate diachronic trajectories for changes.

Niyogi and Berwick provided a model for how new I-languages progress through a community of speakers. This is a remarkable result, which clearly could not be replicated under a social definition of grammars, which denies the usefulness of individual, biological I-languages and engages with categories that are, in my view, too gross, gathering excessively 'big data' like Fries (1940). There may be slowness and gradualness in the spread of a change through a population but changes in I-languages are instantaneous at the individual level; familiar S-curves generally arise as a function of averaging across groups.

This all strongly suggests that structural changes are rapid and abrupt at the individual level and that they often spread through a population rapidly. The speed of the spread depends on non-grammatical factors relating to social cohesion, facility of communication among different groups, etc. 


\section{More on I-languages}

Rather than seeing gradual change in socially defined languages, we see new I-languages spreading through a speech community. We have outlined a different approach here in terms of a distinction between amorphous and shifting E-language, constantly in flux and never experienced the same way by any two people, and biological I-languages represented in the mind/brains of individuals, recursive systems that characterize the individual's language capacity. We view an I-language as emerging in a child as its elements are expressed in the ambient E-language and are discovered and acquired by the child. I-languages are internal, individual entities and speakers typically operate with more than one I-language. Different I-languages may be attained when children are exposed to different E-language.

Construing a person's language capacity as an individual, private matter, we can understand how different linguistic experience may trigger a different internal system, which may then spread through a speech community in ways that can be understood through the methods of population biology. Under this view, discontinuities, new I-languages, are liable to emerge at any time and can be understood as natural phenomena. Nothing abstract is transmitted from one generation to another but children develop an I-language when exposed to E-language that 'expresses' or requires certain structures. A child might develop a novel I-language and that new I-language may spread through a community. That is our understanding of 'language change', a derivative function that is best understood as an individual phenomenon that may affect the linguistic experience of others and lead to a shift in group behavior. By seeking to understand the emergence of new linguistic patterns through the acquisition of language systems by individuals, we can sometimes explain the new group behavior.

Returning now to $\mathrm{E} \& \mathrm{~F}$, we construe their argument in terms of the emergence and spread of new I-languages greatly influenced by the ambient language of speakers of Old Norse, who were allies in opposition to the newly dominant Normans and more prestigious and somewhat more economically successful than speakers of forms of Old English. E\&F have shown that their syntax differed greatly, which comes as no surprise to philologists long impressed by the sharp differences between Old and Middle English. What is novel is the demonstration of the consistently Scandinavian shaping of the new syntax and many new Scandinavian-style I-languages emerged quickly. There was indeed a wholesale catastrophic change, which can be understood in terms of the emergence of new I-lan- 
guages, differing in several structures but in a consistent way, the Scandinavian way. Bech and Walkden are not impressed with that consistency and prefer to think that the similarities are due to 'accident, contact or universals' $(2015,67)$. McWhorter (2016), on the other hand, notes that 'there remains a core of parallels upon which E\&F are convincing, too numerous to be waved away, and almost none of them plausible as chance developments'.

E\&F have advanced a bold and very interesting hypothesis, which will be hard to accept for philologists and linguists taking a non-biological view of the language capacity, given their commitment to seeing languages change only gradually and imperceptibly. E\&F show that radical phase transitions may indeed take place and may explain discontinuities like the long-noted divergence of Middle English from Old English. This represents, in one view of the work, a major change in I-languages with several elements changing to a Scandinavian mode at the same time.

\section{Conclusion}

For Thomason (2016), E\&F's results raise methodological issues, particularly with regard to the genealogical claims E\&F make, notably, in her formulation, their failure to work with the comparative method, 'the most important method in the historical linguist's toolbox'. The comparative method has indeed been important but not for syntactic reconstructions, which have been severely limited, partly because of how new structures emerge, as has long been noted (e.g., Watkins 1976; Lightfoot 1979). The track record of the comparative method in syntactic reconstructions hardly warrants discarding analyses for which substantial evidence has been offered. Instead, it may be necessary to modify ideas about the feasibility of reconstructing prehistoric syntactic systems. This, in turn, raises questions about the nature of the reconstructions, obviously not proto-I-languages. There has been extensive discussion of the problematic nature of such reconstructions in recent years; suffice it to say for now that they cannot be taken as counterevidence to particular I-languages, but E\&F may need to re-think the genealogical claims they are making, not a matter addressed here. ${ }^{5}$

${ }^{5}$ Indeed, it is worth noting in the low light of a footnote, that if we cease to think of languages as objects being transmitted from one generation to another, matters of language genealogy become very hard to think about, even more so the reconstruction of prehistorical proto-languages that are allegedly passed down through generations. 
Once we take on more of Trudgill's 'generativist mindset', emphasizing the acquisition of language and the E-language/I-language dichotomy, we can understand how phase transitions take place. E\&F's hypothesis is intrinsically interesting and is certainly an empirical claim. At a minimum, they have shown in detail that there was a major discontinuity in the development from Old to Middle English and that that discontinuity had a very Scandinavian character, which needs to be explained. Consequently, E\&F's work will stimulate productive research as scholars seek to build on what they have done or alternatively to refute their basic claim. One would expect scholars to be asking why there seems to have been more Norse influence in triggering syntactic properties than lexical or phonological features, why certain syntactic structures of Norse I-languages were not acquired by speakers in England, and why Mainland Scandinavian and English seemed to undergo more common developments after the 14th century. And many other questions that are now on the agenda of diachronic generative syntacticians. ${ }^{6}$

We have few languages with histories attested over several hundred years. Given the predisposition of historical linguists to view those histories as consisting of gradual, imperceptible changes accumulating into larger shifts, it is hardly surprising that we do not have a large stock of wellanalyzed phase transitions. That is no reason to deny even the possibility

This will come as no surprise to those who have followed debates about the dubious methods used in such reconstructions (Campbell \& Harris 2002; Lightfoot 2002a;b). See also Pires \& Thomason (2008). For interesting reflections on attempts to use reconstructions to link work on language and genetic change, see Campbell (2015); Campbell surveys work on language extinction and notes that language replacement, of the kind that $\mathrm{E} \& \mathrm{~F}$ have argued for, is common. For more sympathetic approaches to syntactic reconstruction, see Walkden (2014) and Willis (2011).

${ }^{6}$ Indeed, the resistance to Scandinavian influence in lexical and phonological learning may reflect general differences in the acquisition of syntax on the one hand and phonology and the lexicon on the other; for some considerations, see Heinz \& Idsardi $(2011 ; 2013)$. The acquisition of syntax is entirely a subconscious matter but people are often aware of the words and sounds they use, although not always reliably.

Riny Huybregts (2017) has fascinating reflections on the asymmetry between the mapping of syntax into the sensorimotor (phonological) and conceptual-intentional (logical) interfaces. He speculates on what the differences between the two modes of 'externalization' mean for the evolution of the language faculty in the species and his ideas will surely influence how we think about the acquisition of the mapping operations, the externalizations in speech, sign, etc. He studies click phonemes that occur only in the San languages and argues that the capacity for language and thought existed before human populations separated but that the speech externalization took place long after the population divergences. 
of the catastrophe that E\&F have described in their re-interpretation of the emergence of 'Middle English', now best equipped with scare quotes. We have new and richer ways of understanding catastrophic changes, which, in turn, cast new light on the nature of children's first language acquisition.

\section{Acknowledgments}

Thanks to Marlyse Baptista, Joe Emonds, and Betty Tuller for helpful comments on a preliminary draft.

\section{References}

Adger, David. 2006. Combinatorial variability. Journal of Linguistics 42. 503-530.

Bech, Kristin and George Walkden. 2016. English is (still) a West Germanic language. Nordic Journal of Linguistics 39. 65-100.

Biberauer, Theresa and Marc Richards. 2006. True optionality: When the grammar doesn't mind. In C. Boeckx (ed.) Minimalist essays. Amsterdam \& Philadelphia: John Benjamins. 35-67.

Campbell, Lyle. 2015. Do languages and genes correlate? Some methodological issues. Language Dynamics and Change 5. 202-226.

Campbell, Lyle and Alice Harris. 2002. Syntactic reconstruction and demythologizing "Myths and the prehistory of grammars". Journal of Linguistics 38. 599-618.

Casti, John. 1994. Complexification: Explaining a paradoxical world through the science of surprise. New York: HarperCollins.

Chomsky, Noam. 1965. Aspects of the theory of syntax. Cambridge, MA: MIT Press.

Chomsky, Noam. 1986. Knowledge of language: Its nature, origin and use. New York: Praeger.

Eldridge, Niles and Stephen Jay Gould. 1972. Punctuated equilibria: An alternative to phyletic gradualism. In T. J. M. Schopf (ed.) Models of paleobiology. San Francisco: Freeman Cooper. 82-115.

Emonds, Joseph and Jan Terje Faarlund. 2014. English: The language of the Vikings. Olomouc: Palacky University Press.

Fries, Charles. 1940. On the development of the structural use of word-order in Modern English. Language 16. 199-208.

Gleick, James. 1987. Chaos: Making a new science. New York: Viking Penguin.

Haeberli, Eric. 2002a. Inflectional morphology and the loss of verb second in English. In Lightfoot (2002c, 88-106).

Haeberli, Eric. 2002b. Observations on the loss of verb second in the history of English. In J.-W. Zwart and W. Abraham (eds.) Studies in comparative Germanic syntax: Proceedings from the 15th Workshop on Comparative Germanic Syntax. Amsterdam \& Philadelphia: John Benjamins. 245-272. 
Haeberli, Eric and Tabea Ihsane. to appear. The recategorization of modals in English: Evidence from adverb placement. In B. Egedi and V. Hegedús (eds.) Functional heads across time: Syntactic re-analysis and change. Oxford: Oxford University Press.

Haken, Hermann. 1984. The science of structure: Synergetics. New York: Van Nostrand Reinhold.

Heinz, Jeffrey and William Idsardi. 2011. Sentence and word complexity. Science 333. 295-297.

Heinz, Jeffrey and William Idsardi. 2013. What complexity differences reveal about domains in language. Topics in Cognitive Science 5. 111-131.

Hockett, Charles F. 1958. A course in modern linguistics. New York: Macmillan.

Holmberg, Anders. 2016. Norse against Old English. Language Dynamics and Change 6. $21-23$.

Humboldt, Wilhelm von. 1836. Über die Verschiedenheit des menschlichen Sprachbaues und ihren Einfluss auf die geistige Entwicklung des Menschengeschlechts. Berlin: Königlichen Akademie der Wissenschaften.

Huybregts, M. A. C. (Riny). 2017. Phonemic clicks and the mapping asymmetry: How language emerged and speech developed. Neuroscience and Behavioral Reviews 81. 279-294.

Kauffman, Stuart. 1995. At home in the universe: The search for laws of self-organisation and complexity. Oxford: Oxford University Press.

Kemenade, Ans van. 1987. Syntactic case and morphological case in the history of English. Dordrecht: Foris.

Kiparsky, Paul. 1968. Linguistic universals and linguistic change. In E. Bach and R. T. Harms (eds.) Universals in linguistic theory. New York: Holt, Rinehart and Winston. $171-202$.

Kroch, Anthony. 1989. Reflexes of grammar in patterns of language change. Language Variation and Change 1. 199-244.

Kroch, Anthony. 1994. Morphosyntactic variation. In K. Beals, J. Denton, R. Knippen, L. Melnar, H. Suzuki and E. Zeinfeld (eds.) Papers from the 30th Regional Meeting of the Chicago Linguistic Society. Volume 2: The Parasession on Variation and Linguistic Theory. Chicago: Chicago Linguistic Society. 180-201.

Ledgeway, Adam and Ian G. Roberts (eds.). 2017. Cambridge handbook of historical syntax. Cambridge: Cambridge University Press.

Lightfoot, David W. 1979. Principles of diachronic syntax. Cambridge: Cambridge University Press.

Lightfoot, David W. 1989. The child's trigger experience: Degree-0 learnability. Behavioral and Brain Sciences 12. 321-334.

Lightfoot, David W. 1999. The development of language: Acquisition, change, and evolution. Malden, MA \& Oxford: Blackwell.

Lightfoot, David W. 2002a. More myths. Journal of Linguistics 38. 619-626.

Lightfoot, David W. 2002b. Myths and the prehistory of grammars. Journal of Linguistics 38. $113-136$.

Lightfoot, David W. (ed.). 2002c. Syntactic effects of morphological change. Oxford: Oxford University Press. 
Lightfoot, David W. 2006. How new languages emerge. Cambridge: Cambridge University Press.

Lightfoot, David W. 2012. Explaining matrix/subordinate domain discrepancies. In L. Aelbrecht, L. Haegeman and R. Nye (eds.) Main clause phenomena. Amsterdam \& Philadelphia: John Benjamins. 159-176.

Lightfoot, David W. 2016. Review of Emonds and Faarlund 2014. Language 92. 474-477.

Lightfoot, David W. 2017a. Discovering variable properties. Linguistic Analysis 41. 409-444.

Lightfoot, David W. 2017b. Imperfect transmission and discontinuity. In Ledgeway \& Roberts $(2017,515-533)$.

Lightfoot, David W. 2020. Born to parse: How children select their languages. Cambridge, MA: MIT Press.

McWhorter, John. 2016. Too good to be true; English is not Norse. Language Dynamics and Change 6. 34-36.

Niyogi, Partha. 2006. The computational nature of language learning and evolution. Cambridge, MA: MIT Press.

Niyogi, Partha and Robert Berwick. 1995. The logical problem of language change. MIT A.I. Memo 1516.

Niyogi, Partha and Robert Berwick. 1997. A dynamical systems model of language change. Complex Systems 11. 161-204.

O'Neil, Wayne. 1978. The evolution of the Germanic inflectional systems: A study in the causes of language change. Orbis 27. 248-285.

Paul, Hermann. 1877. Die Vocale der Flexions- und Ableitungssilben in den ältesten germanischen Dialecten. Beiträge zur Geschichte der deutschen Sprache und Literatur 4. $314-475$.

Paul, Hermann. 1880. Prinzipien der Sprachgeschichte. Tübingen: Niemeyer.

Pintzuk, Susan. 2002. Verb-object order in Old English: Variation as grammatical competition. In Lightfoot (2002c, 276-299).

Pires, Acrisio and Sarah G. Thomason. 2008. How much syntactic reconstruction is possible? In G. Ferraresi and M. Goldbach (eds.) Principles of syntactic reconstruction. Amsterdam \& Philadelphia: John Benjamins. 27-72.

Roeper, Thomas. 1999. Universal bilingualism. Manuscript, University of Massachusetts, Amherst.

Thom, René. 1972. Stabilité structurelle et morphogénèse: Essai d'une théorie générale des modèles. Reading, MA: W. A. Benjamin.

Trudgill, Peter. 2016. Norsified English or anglicized Norse? Language Dynamics and Change 6. 46-48.

Walkden, George. 2014. Syntactic reconstruction and Proto-Germanic. Oxford: Oxford University Press.

Wallenberg, Joel C. 2016. Extraposition is disappearing. Language 92. e237-e256.

Watkins, Calvert. 1976. Toward Proto-Indo-European syntax: Problems and pseudo-problems. In S. Steever, C. Walker and S. Mufwene (eds.) Papers from the parasession on diachronic syntax. Chicago: Chicago Linguistic Society. 305-393. 
Weinreich, Uriel, William Labov and Marvin I. Herzog. 1968. Empirical foundations for a theory of language change. In W. P. Lehmann and Y. Malkiel (eds.) Directions for historical linguistics: A symposium. Austin, TX: University of Texas Press. 95-189.

Westergaard, Marit. 2017. Gradience and gradualness vs abruptness. In Ledgeway \& Roberts (2017, 446-466).

Willis, David. 2011. Reconstructing last week's weather: Syntactic reconstruction and Brythonic free relatives. Journal of Linguistics 47. 407-446.

Yang, Charles D. and Thomas Roeper. 2011. Minimalism and language acquisition. In C. Boeckx (ed.) The Oxford handbook of linguistic minimalism. Oxford: Oxford University Press. 551-573. 
